\title{
Article \\ A Simple and Ultrasensitive Colorimetric Biosensor for Anatoxin-a Based on Aptamer and Gold Nanoparticles
}

\author{
Duy-Khiem Nguyen (1) and Chang-Hyun Jang * \\ Department of Chemistry, Gachon University, Seongnam-daero 1342, Sujeong-gu, Seongnam-si 13120, Korea; \\ khiem80@gachon.ac.kr \\ * Correspondence: chjang4u@gachon.ac.kr; Tel.: +82-31-750-8555
}

\begin{abstract}
Here, we designed a simple, rapid, and ultrasensitive colorimetric aptasensor for detecting anatoxin-a (ATX-a). The sensor employs a DNA aptamer as the sensing element and gold nanoparticles (AuNPs) as probes. Adsorption of the aptamer onto the AuNP surface can protect AuNPs from aggregation in $\mathrm{NaCl}$ solution, thus maintaining their dispersion state. In the presence of ATX-a, the specific binding of the aptamer with ATX-a results in a conformational change in the aptamer, which facilitates AuNP aggregation and, consequently, a color change of AuNPs from red to blue in $\mathrm{NaCl}$ solution. This color variation is directly associated with ATX-a concentration and can be easily measured using a UV/Vis spectrophotometer. The absorbance variation is linearly proportional to ATX-a concentration across the concentration range of $10 \mathrm{pM}$ to $200 \mathrm{nM}$, with a detection limit of $4.45 \mathrm{pM}$ and high selectivity against other interferents. This strategy was successfully applied to the detection of ATX-a in lake water samples. Thus, the present aptasensor is a promising alternative method for the rapid detection of ATX-a in the environment.
\end{abstract}

Keywords: anatoxin-a; colorimetric aptasensors; aptamer; UV/Vis absorbance; gold nanoparticles

Citation: Nguyen, D.-K.; Jang, C.-H.

A Simple and Ultrasensitive

Colorimetric Biosensor for Anatoxin-a Based on Aptamer and Gold Nanoparticles. Micromachines 2021, 12, 1526. https://doi.org/ $10.3390 /$ mi12121526

Academic Editor: Mengdi Han

Received: 17 November 2021

Accepted: 7 December 2021

Published: 8 December 2021

Publisher's Note: MDPI stays neutral with regard to jurisdictional claims in published maps and institutional affiliations.

Copyright: (C) 2021 by the authors. Licensee MDPI, Basel, Switzerland. This article is an open access article distributed under the terms and conditions of the Creative Commons Attribution (CC BY) license (https:/ / creativecommons.org/licenses/by/ $4.0 /)$.

\section{Introduction}

Anatoxin-a (ATX-a) is a natural organophosphate neurotoxin, produced by various cyanobacteria including Aphanizomenon gracile, Oscillatoria acuminata, and Anabaena flosaquae, which occur naturally in freshwater [1,2]. This toxin can irreversibly bind to nicotinic acetylcholine receptors, leading to disruption of oxygen supply to the brain, causing respiratory paralysis, acute asphyxia, and ultimately death [2,3]. Exposure to ATX-a primarily occurs through the ingestion of contaminated water $[1,3]$. In recent years, an increase in animal intoxication due to ATX-a has been observed [2]. Thus, the development of a sensitive and accurate method for ATX-a detection is urgently needed to monitor and control the quality of both environmental water and drinking water.

To date, only a limited range of analytical techniques have been developed for ATX-a detection, such as electrochemistry [1], liquid chromatography-mass spectrometry (LCMS/MS) [2], high-performance liquid chromatography (HPLC) [4], gas chromatographymass spectrometry (GC-MS) [5], fluorescence [6], and electrochemiluminescence [7]. However, these techniques have several limitations including bulk and expensive instrumentation, complex sample preparation, time-consuming procedures, and the need for highly skilled personnel for operation [6,7]. Therefore, a much simpler, cost-effective, and precise alternative needs to be urgently developed for ATX-a detection.

In recent years, aptamer-based colorimetric sensing methods have emerged as alternatives to detect various target molecules [8-13], because of their simplicity, low cost, high sensitivity, and specific detection without the requirement of complex instrumentation [14]. In this assay, aptamers (single-stranded DNA or RNA oligonucleotides) are used as recognition elements owing to their ability to selectively bind their target molecules, which helps improve the sensor specificity [15-20]. Furthermore, aptamers have the distinctive advantages of high stability, high selectivity, and cost-effectiveness [21]. An aptamer for 
ATX-a was previously selected, characterized, and used as a recognition probe to develop a simple impedimetric aptasensor for ATX-a sensing [1].

In colorimetric sensors, gold nanoparticles (AuNPs) are commonly used as colorimetric reporters because of their high extinction coefficients and size-dependent optical properties $[8,22]$. The color of the dispersed AuNP solution is wine-red. However, aggregation of AuNPs increases the size of the particles, resulting in remarkable color changes of the solution from wine-red to purple or blue, which can be observed by the naked eye [22-24]. In addition, AuNPs have been used in combination with other nanomaterials (e.g., reduced graphene oxide) or conjugated with aptamers to improve the performance of the sensors or to enhance the detection sensitivity [25-27]. Moreover, AuNPs can adsorb unfolded aptamers through electrostatic and noncovalent interactions, which protects AuNPs from salt-induced aggregation by enhancing the electrostatic repulsion between nanoparticles $[8,22,28]$. However, when aptamers bind to their target molecules, their conformation changes. The exposure of nucleobases on aptamers is reduced, and a negatively charged phosphate backbone is presented. This leads to poor adsorption of the aptamers onto the AuNP surface; therefore, the target-bound aptamers cannot prevent the aggregation of AuNPs in solutions with high salt concentration, resulting in color changes in the nanoparticle solution [24,29]. Recently, colorimetric biosensors were integrated with a smartphone for the development of personalized point-of-care (POC) devices that can be used for self-monitoring of physical health parameters [30]. For example, Qing et al. developed a colorimetric assay using a smartphone RGB camera for self-monitoring of diabetes [31].

In this study, we developed a simple, label-free colorimetric biosensing system for the sensitive detection of ATX-a using DNA aptamers as the target recognition elements and gold nanoparticles as colorimetric reporters. In the absence of ATX-a, the random coil aptamer adsorbs onto the surface of citrate-capped AuNPs and protects them from aggregation in $\mathrm{NaCl}$ solution; thus, the AuNPs maintain their dispersion state and the solution remains red in color (Figure 1). In the presence of ATX-a, the specific binding of aptamers with ATX-a alters the conformation of the aptamer, which reduces the adsorption of the aptamer on the AuNP surface, leading to AuNP aggregation and, consequently, a color change of the solution from red to blue under high $\mathrm{NaCl}$ concentration. By measuring the color and absorbance change of the AuNP solution, the concentration of ATX-a can be easily quantified. Our results indicate that the proposed colorimetric aptasensor platform can detect ATX-a in aqueous solutions at the picomolar level $(4.45 \mathrm{pM})$ with high selectivity against other interferents. Furthermore, the aptasensor is simple and easy to operate, and it does not require expensive and sophisticated instruments. 


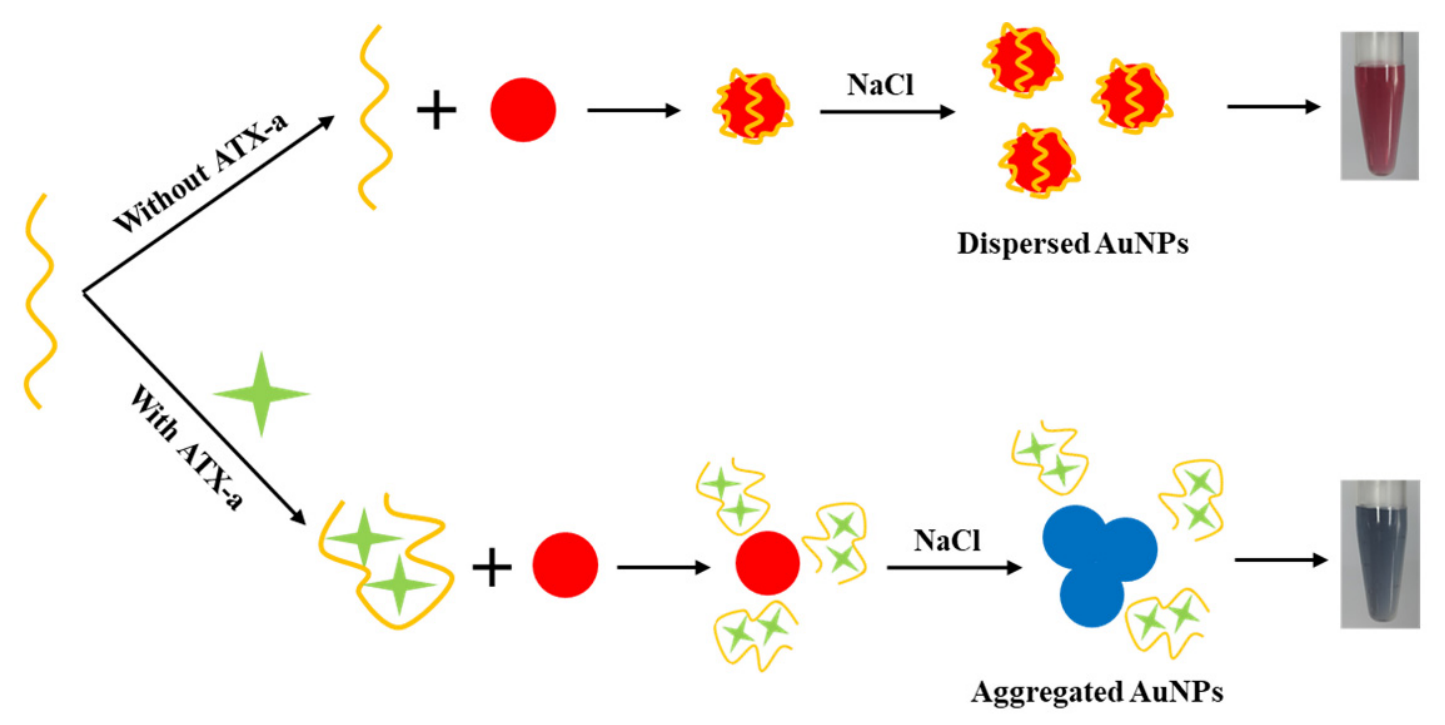

ATX-a aptamer
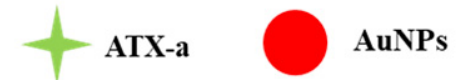

Compound of ATX-a and aptamer

Figure 1. Schematic illustration of the colorimetric aptasensor for anatoxin-a (ATX-a) detection based on gold nanoparticle aggregation under high $\mathrm{NaCl}$ concentration.

\section{Materials and Methods}

\subsection{Materials and Apparatus}

The anatoxin-a-specific aptamer with the sequence 5'-TGG CGA CAA GAA GAC GTA CAA ACA CGC ACC AGG CCG GAG TGG AGT ATT CTG AGG TCG G-3' was purchased from Mbiotech (Hanam, South Korea). Anatoxin-a fumarate salt (ATX-a), aflatoxin (AFT), cylindrospermopsin solution (CYN), microcystin-LR solution (MC-LR), $\mathrm{HAuCl}_{4} \cdot 3 \mathrm{H}_{2} \mathrm{O}$, sodium citrate $\left(\mathrm{Na}_{3} \mathrm{C}_{6} \mathrm{H}_{5} \mathrm{O}_{7} \cdot 2 \mathrm{H}_{2} \mathrm{O}\right)$, calcium chloride $\left(\mathrm{CaCl}_{2}\right)$, magnesium chloride $\left(\mathrm{MgCl}_{2}\right)$, potassium chloride $(\mathrm{KCl})$, and sodium chloride $(\mathrm{NaCl})$ were obtained from Sigma-Aldrich (St. Louis, $\mathrm{MO}, \mathrm{USA}) . \mathrm{HCl}(36 \%)$ and $\mathrm{HNO}_{3}(70 \%)$ were obtained from Daejung Chemicals \& Metals Co., Ltd. (Daejung, South Korea). Citrate-coated AuNPs (15 nm mean diameter) with a concentration of approximately $4.7 \mathrm{nM}$ were synthesized using the citrate reduction method as reported previously [32]. Deionized (DI) water from a Milli-Q water purification system (Millipore, CA, USA) was used to prepare the aqueous solutions.

The shape, size, and aggregation of AuNPs were examined by transmission electron spectroscopy (TEM, Tecnai G2 F30 S-TWIN) at $300 \mathrm{kV}$. UV/Vis absorption spectra were recorded using a UV/Vis spectrophotometer (Cary 50, Varian).

\subsection{Optimization of Detection Conditions}

To optimize the $\mathrm{NaCl}$ concentration, $\mathrm{NaCl}$ solutions with different concentrations were mixed with the AuNP solution and incubated for $5 \mathrm{~min}$ at $25^{\circ} \mathrm{C}$. The total volume of the mixture was $1.5 \mathrm{~mL}$. The final concentrations of $\mathrm{NaCl}$ were $0,10,20,30,40,50$, and $60 \mathrm{mM}$. The absorbance value at $524 \mathrm{~nm}$ of each sample was then measured using a UV/Vis spectrophotometer.

To optimize the aptamer concentration, different concentrations of aptamer $(0,50,100$, $125,150,175$, and $200 \mathrm{nM}$ ) were mixed with the AuNP solution and incubated for $2 \mathrm{~h}$ at $25^{\circ} \mathrm{C}$. NaCl solution $(1.5 \mathrm{M})$ was then added, and the mixtures were incubated for $5 \mathrm{~min}$ at $25^{\circ} \mathrm{C}$. The total volume of the mixture was $1.5 \mathrm{~mL}$, and the final concentration of $\mathrm{NaCl}$ was $40 \mathrm{mM}$. 


\subsection{Colorimetric Detection of ATX-a}

In a typical experiment, $60 \mu \mathrm{L}$ of $3 \mu \mathrm{M}$ aptamer solution and $60 \mu \mathrm{L}$ of ATX-a solution at different concentrations (final ATX-a concentrations were $0,0.01,0.1,1,10,100$, and $200 \mathrm{nM}$ ) were mixed in a $1.5 \mu \mathrm{L}$ centrifuge tube and incubated at $37^{\circ} \mathrm{C}$ for $2 \mathrm{~h}$. Next, $1340 \mu \mathrm{L}$ of AuNP solution was added to the assay solution, mixed well, and incubated for $2 \mathrm{~h}$ at room temperature $\left(\sim 25^{\circ} \mathrm{C}\right)$. Finally, $40 \mu \mathrm{L}$ of $1.5 \mathrm{M} \mathrm{NaCl}$ solution was added to the centrifuge tube at room temperature $\left(\sim 25^{\circ} \mathrm{C}\right)$. After $5 \mathrm{~min}, 1.5 \mathrm{~mL}$ of the resulting solution was transferred to a quartz cuvette, and the absorbance of the solutions was recorded. The absorbance values of each sample at $524 \mathrm{~nm}\left(\mathrm{~A}_{524}\right)$ were determined, and the difference between the absorbance of samples with ATX-a and the absorbance of the blank sample at $524 \mathrm{~nm}\left(\Delta \mathrm{A}_{524}\right)$ was calculated.

To test the specificity of the present aptasensor, some common interferents such as aflatoxin (AFT), cylindrospermopsin (CYN), microcystin-LR (MC-LR), $\mathrm{CaCl}_{2}, \mathrm{MgCl}_{2}$, and $\mathrm{KCl}$ were also tested.

\section{Results and Discussion}

\subsection{Feasibility of the Colorimetric Assay for ATX-a Detection}

The AuNPs synthesized by citrate reduction of $\mathrm{HAuCl}_{4}$ are wine-red in color and dispersed well in an aqueous solution owing to the electrostatic repulsion produced by the negative charges of citrate anions coated on the AuNP surface $[14,28]$. To prove the feasibility of this assay for ATX-a detection using AuNPs as colorimetric probes, the UV/visible absorption spectra of AuNP solutions before and after treatment with different substances were recorded. The absorption spectrum of pure AuNPs had a strong absorbance peak at $524 \mathrm{~nm}$ (curve 1 in Figure 2), indicating that the AuNPs were well dispersed in the solution. However, after incubation with $40 \mathrm{mM} \mathrm{NaCl}$, the intensity of the absorbance peak at $524 \mathrm{~nm}$ dramatically decreased, implying that the AuNPs aggregated (curve 3 in Figure 2). This is due to the negative charges of citrates coated on the AuNP surface being neutralized by $\mathrm{Na}^{+}$ions, leading to a reduction in electrostatic repulsion and subsequent AuNP aggregation [9,24]. DNA aptamers have been reported to be adsorbed onto the AuNP surface, thus enhancing the electrostatic repulsion between nanoparticles, and protecting AuNPs from NaCl-induced aggregation [22,33]. Therefore, upon aptamer addition to the AuNP solution, the intensity of the absorbance peak at $524 \mathrm{~nm}$ decreased only slightly compared to that of pure AuNPs, indicating that the AuNPs were still dispersed (curve 4 in Figure 2). However, upon the addition of both aptamers and ATX-a, the absorbance at $524 \mathrm{~nm}$ decreased drastically, indicating the aggregation of AuNPs (curve 5 in Figure 2). The ATX-a aptamer undergoes a conformational change induced by the specific binding of aptamers and ATX-a. This change reduces the aptamer adsorption on the AuNP surface, thus diminishing the protective effect of the aptamer and leading to AuNP aggregation [1,9].

The aggregation states of AuNPs under different conditions were further confirmed by transmission electron spectroscopy (TEM). Figure 3a shows that the free AuNPs were well dispersed in the solution and had a spherical morphology with a mean diameter of $15 \mathrm{~nm}$. Addition of $40 \mathrm{mM} \mathrm{NaCl}$ caused complete aggregation of the AuNPs (Figure 3b). In the presence of the aptamer, the AuNPs aggregated slightly after 5 min of incubation with $40 \mathrm{mM} \mathrm{NaCl}$ (Figure 3c). However, in the presence of both the aptamer and ATX-a, obvious aggregation of AuNPs was observed in the presence of $40 \mathrm{mM} \mathrm{NaCl}$ (Figure 3d). These results are consistent with the results obtained from UV/Vis absorption spectra. 


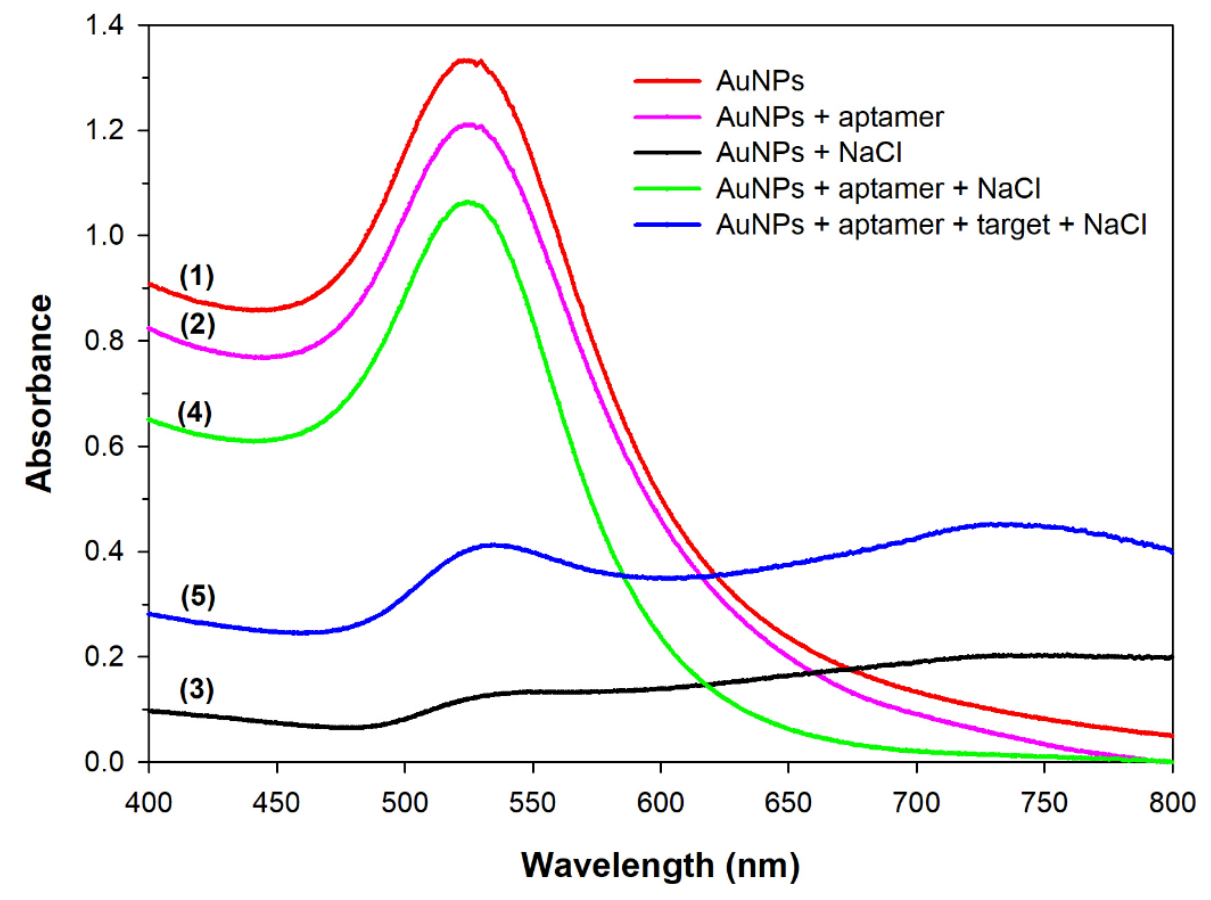

Figure 2. UV/visible absorption spectra of gold nanoparticle (AuNP) solutions after mixing and incubating with different substances: (1) pure AuNPs, (2) AuNPs + anatoxin-a (ATX-a) aptamer, (3) AuNPs + $\mathrm{NaCl},(4)$ AuNPs + ATX-a aptamer + NaCl, and (5) AuNPs + ATX-a aptamer + ATX-a + NaCl.

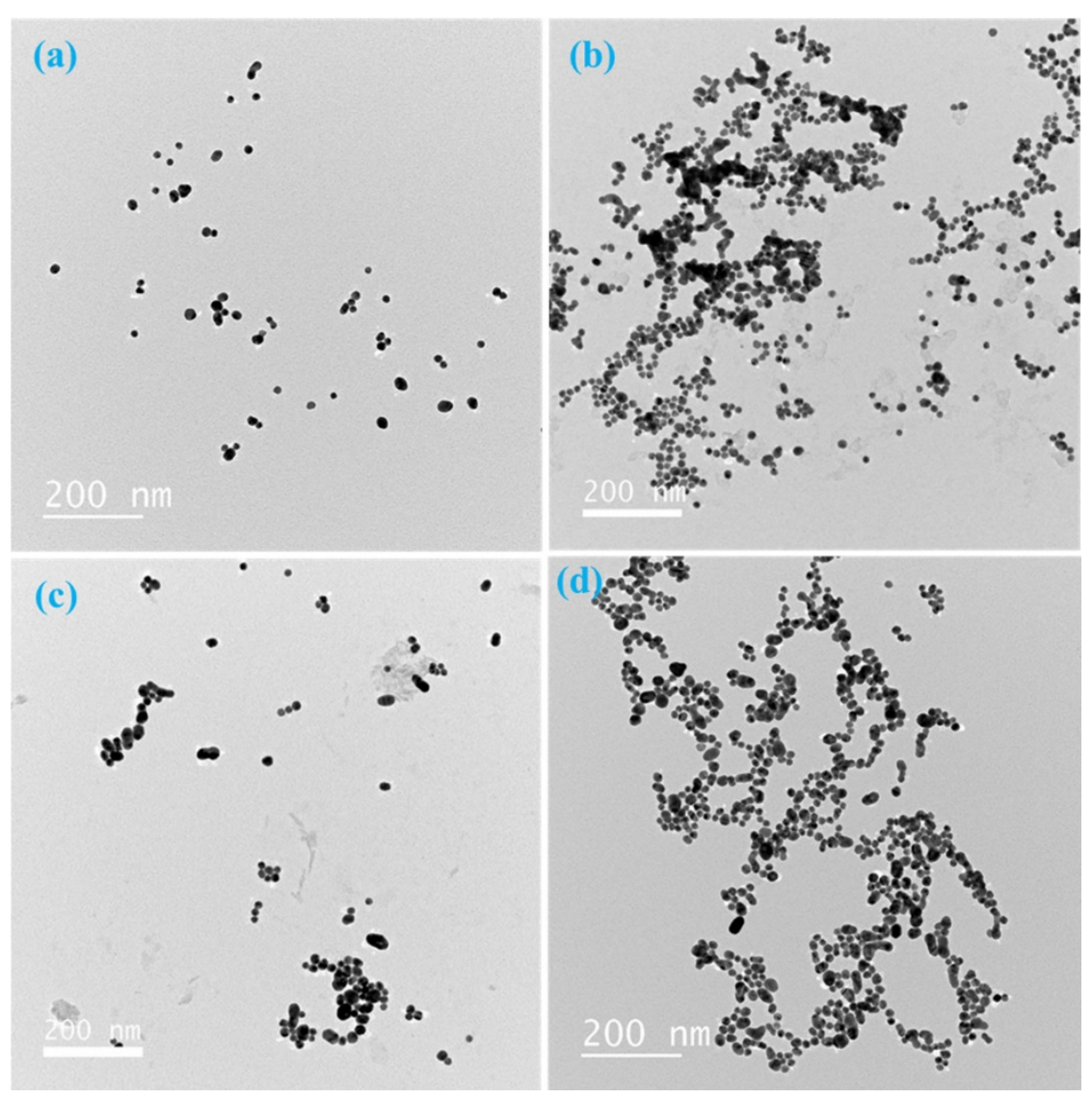

Figure 3. Transmission electron microscopy (TEM) images of gold nanoparticles (AuNPs) in different systems: (a) pure AuNPs, (b) AuNPs + $40 \mathrm{mM} \mathrm{NaCl}$, (c) AuNPs + $125 \mathrm{nM}$ anatoxin-a (ATX-a) aptamer + $40 \mathrm{mM} \mathrm{NaCl}$, and (d) AuNPs + 125 nM ATX-a aptamer + 100 nM ATX-a + 40 mM NaCl. 


\subsection{Optimization of the Detection Conditions}

As $\mathrm{NaCl}$ causes AuNP aggregation and directly affects the performance of the colorimetric assay, the concentration of $\mathrm{NaCl}$ was first optimized. Figure $4 \mathrm{~A}$ shows that the absorbance of the AuNP solution at $524 \mathrm{~nm}$ gradually decreased and the color of the solutions changed from wine-red to blue (inset of Figure 4A) as the $\mathrm{NaCl}$ concentration increased. The lowest absorbance intensity was achieved with $40 \mathrm{mM} \mathrm{NaCl}$, suggesting that the AuNPs were completely aggregated (Figure 4B). Thus, $40 \mathrm{mM} \mathrm{NaCl}$ was used for the subsequent experiments.
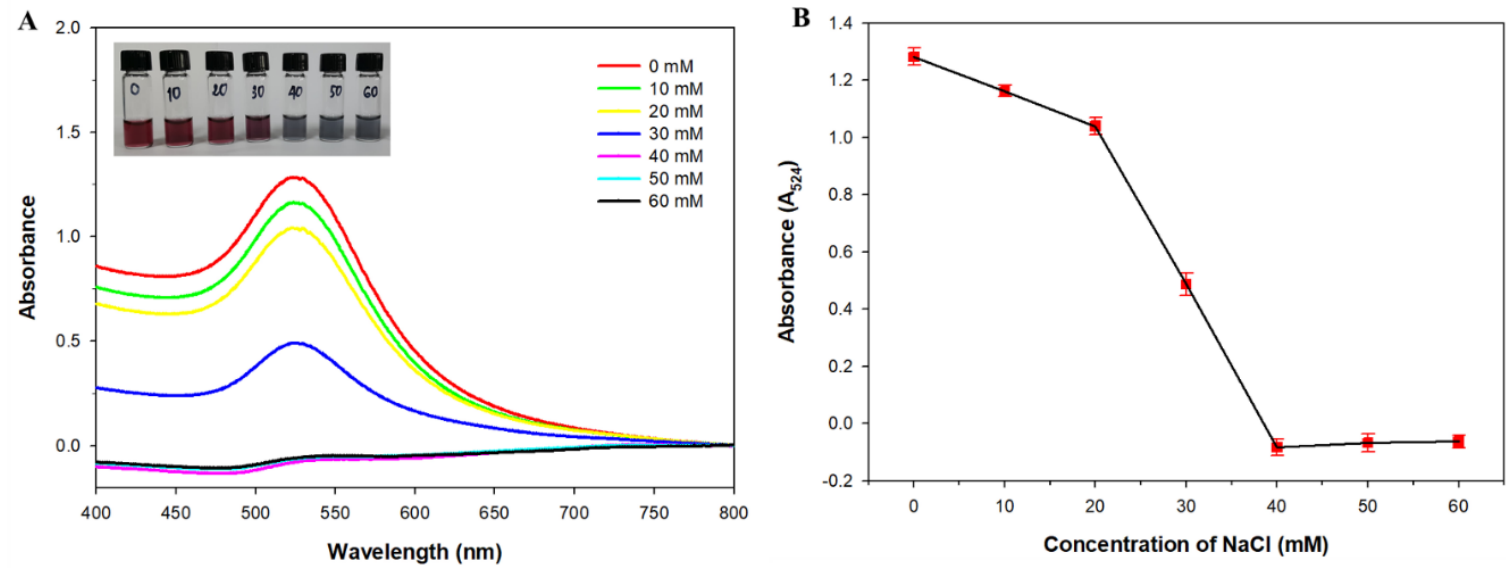

Figure 4. The UV/Vis absorption spectra (A) and absorbance intensity changes at $524 \mathrm{~nm}$ (B) of the gold nanoparticle $(\mathrm{AuNP})$ solutions in the presence of various concentrations of $\mathrm{NaCl}$. Inset: visible color changes of the AuNP solutions.

Aptamer concentration is also an important factor that affects the sensitivity and performance of colorimetric assays. To obtain the optimal aptamer concentration, different concentrations of the aptamer in the range of 0-200 nM were mixed with the AuNP solution and incubated for $2 \mathrm{~h}$ at $25^{\circ} \mathrm{C}$, followed by the addition of $40 \mathrm{mM} \mathrm{NaCl}$ solution. The result showed that the absorbance intensity at $524 \mathrm{~nm}$ reached the maximum value at an aptamer concentration of $125 \mathrm{nM}$, suggesting the highest protective effect of the aptamer against $\mathrm{NaCl}$-induced aggregation (Figure 5). Therefore, the optimal aptamer concentration was $125 \mathrm{nM}$.
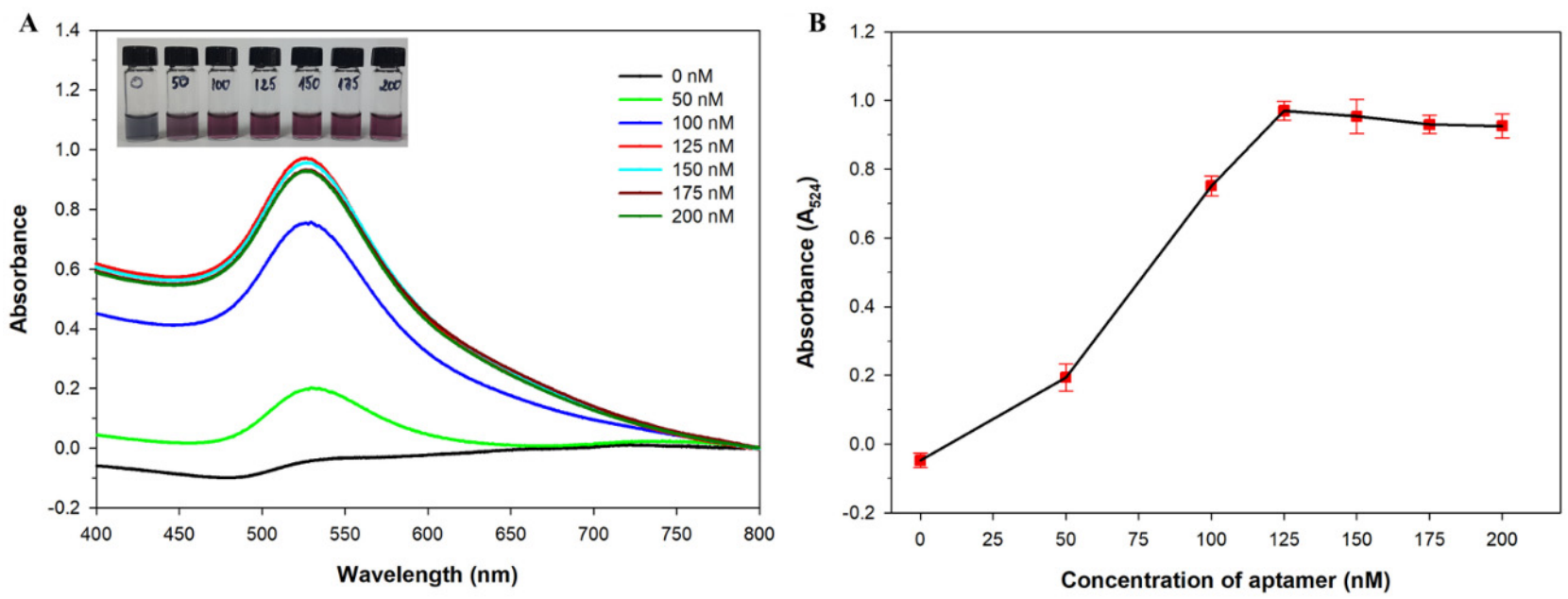

Figure 5. The UV/Vis absorption spectra (A) and absorbance intensity changes at $524 \mathrm{~nm}$ (B) of the gold nanoparticle (AuNP) solutions containing different concentrations of anatoxin-a aptamer after the addition of $40 \mathrm{mM} \mathrm{NaCl}$. Inset: visible color changes of AuNP solutions. 
Incubation time is also an important factor to be considered because it can affect the performance of the biosensor. As illustrated in Figure S1, the optimal incubation time of aptamer with AuNPs was $2 \mathrm{~h}$, and the optimal binding time of aptamer with ATX-a was $2 \mathrm{~h}$.

The adsorption of the DNA aptamer onto the AuNP surface may be affected by the $\mathrm{pH}$ value of the solution. A previous study demonstrated that the highest sensitivity of the sensor was observed at the $\mathrm{pH}$ value of 7.0 [11]. Therefore, in our proposed colorimetric assay, the detection of anatoxin-a was performed at $\mathrm{pH}$ 7.0.

\subsection{Sensitivity, Specificity, Repeatability, and Stability of the Colorimetric Assay for ATX-a Detection}

The proposed colorimetric aptasensor was then applied for ATX-a detection under the optimized experimental conditions. A series of varying concentrations of ATX-a was added, and the UV/Vis absorption spectra of the solutions were recorded. The relationship between the absorbance variation $\left(\Delta \mathrm{A}_{524}\right)$ and ATX-a concentration was then investigated. As presented in Figure 6A, the color of the AuNP solutions gradually changed from winered to purple and blue (inset of Figure 6A), and the absorbance of AuNPs at $524 \mathrm{~nm}$ gradually decreased with increasing ATX-a concentration. The absorbance variation was linearly proportional to the logarithmic concentration of ATX-a across the concentration range of $10 \mathrm{pM}$ to $200 \mathrm{nM}$ (Figure $6 \mathrm{~B}$ ). The linear regression equation was $\Delta \mathrm{A}_{524}=0.2379$ $\log C_{\text {ATX-a }}-0.2399\left(R^{2}=0.99\right)$. The detection limit (LOD) of ATX-a was calculated to be $4.45 \mathrm{pM}$, which was determined using the equation $3 \alpha / \mathrm{m}$, where $\alpha$ is the standard deviation of blank and $\mathrm{m}$ is the slope of the calibration curve [26,34]. Compared to other existing techniques for ATX-a detection such as HPLC, GC-MS, electrochemistry, fluorescence, and electrochemiluminescence, the proposed colorimetric assay exhibits a wider linear range and a lower LOD for ATX-a, as summarized in Table 1.
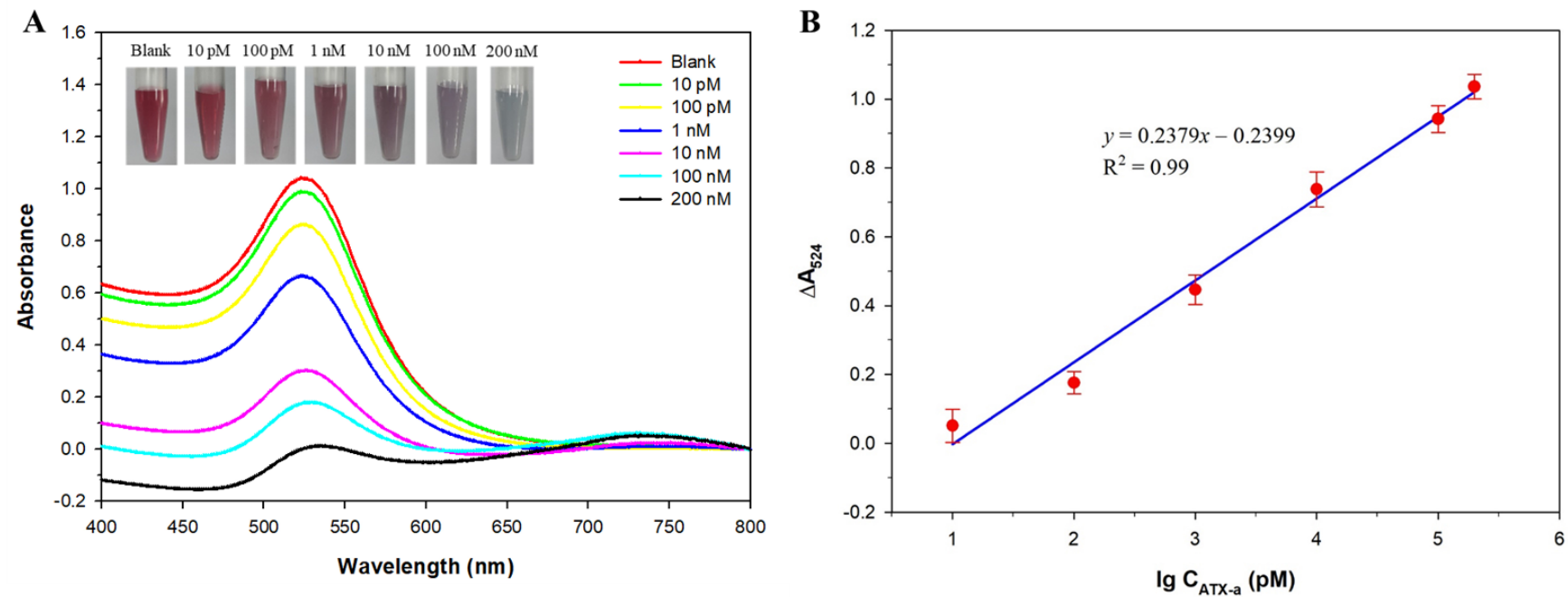

Figure 6. (A) The UV/Vis absorption spectra of the gold nanoparticle (AuNP) solutions in the presence of mixtures of $125 \mathrm{nM}$ aptamer and various concentrations of anatoxin-a (ATX-a) after incubation with $40 \mathrm{mM} \mathrm{NaCl}$ for $5 \mathrm{~min}$ (inset: visible color changes of AuNP solutions). (B) Derived calibration curve showing the variation of relative absorbance at $524 \mathrm{~nm}\left(\mathrm{~A}_{524}\right)$ versus the logarithmic concentration of ATX-a.

The specificity of the proposed biosensor was investigated. To test specificity, ATX-a $(200 \mathrm{nM})$ and other common interferents (all at $1 \mu \mathrm{M})$ such as aflatoxin (AFT), cylindrospermopsin $(\mathrm{CYN})$, microcystin-LR (MC-LR), $\mathrm{CaCl}_{2}, \mathrm{MgCl}_{2}$, and $\mathrm{KCl}$ were tested under the same optimized experimental conditions. As illustrated in Figure 7, the change in absorbance at $524 \mathrm{~nm}$ for the target ATX-a was significant, whereas it was negligible for the other interferents. The results indicated that the proposed colorimetric aptasensor has 
excellent specificity toward ATX-a, which can be attributed to the highly specific binding of ATX-a aptamers with ATX-a.

Table 1. Comparison with reported methods for anatoxin-a detection.

\begin{tabular}{|c|c|c|c|}
\hline Methods & Linear Ranges & Limit of Detection & Reference \\
\hline Electrochemistry & $1-100 \mathrm{nM}$ & $0.5 \mathrm{nM}$ & [1] \\
\hline HPLC $^{a}$ & $0.3-9.078 \mu \mathrm{M}$ & $121 \mathrm{nM}$ & [4] \\
\hline GC-MS b & $2.5-200 \mathrm{ng} / \mathrm{mL}$ & $2 \mathrm{ng} / \mathrm{mL}$ & [5] \\
\hline Fluorescence & - & $<3 \mathrm{nM}$ & [6] \\
\hline Electrochemiluminescence & $1-1000 \mathrm{mg} / \mathrm{L}$ & $0.34 \mathrm{mg} / \mathrm{L}$ & [7] \\
\hline Colorimetric aptasensor & $10 \mathrm{pM}-200 \mathrm{nM}$ & $4.45 \mathrm{pM}$ & Present study \\
\hline
\end{tabular}

a HPLC, high-performance liquid chromatography. ${ }^{\mathrm{b}}$ GC-MS, gas chromatography-mass spectrometry.

Five replicate measurements of ATX-a $(200 \mathrm{nM})$ were carried out under the optimal conditions to check the repeatability of the developed sensor. The relative standard deviation was 3.6\%, suggesting excellent repeatability.

To assess the stability of the developed sensor, the synthesized AuNPs were stored at room temperature $\left(\sim 25^{\circ} \mathrm{C}\right)$ and used to determine ATX-a once a day. After 10 days, the absorbance value of $200 \mathrm{nM}$ ATX-a remained stable, and the relative standard deviation was $<5 \%$, indicating excellent stability of the developed sensor for ATX-a detection.

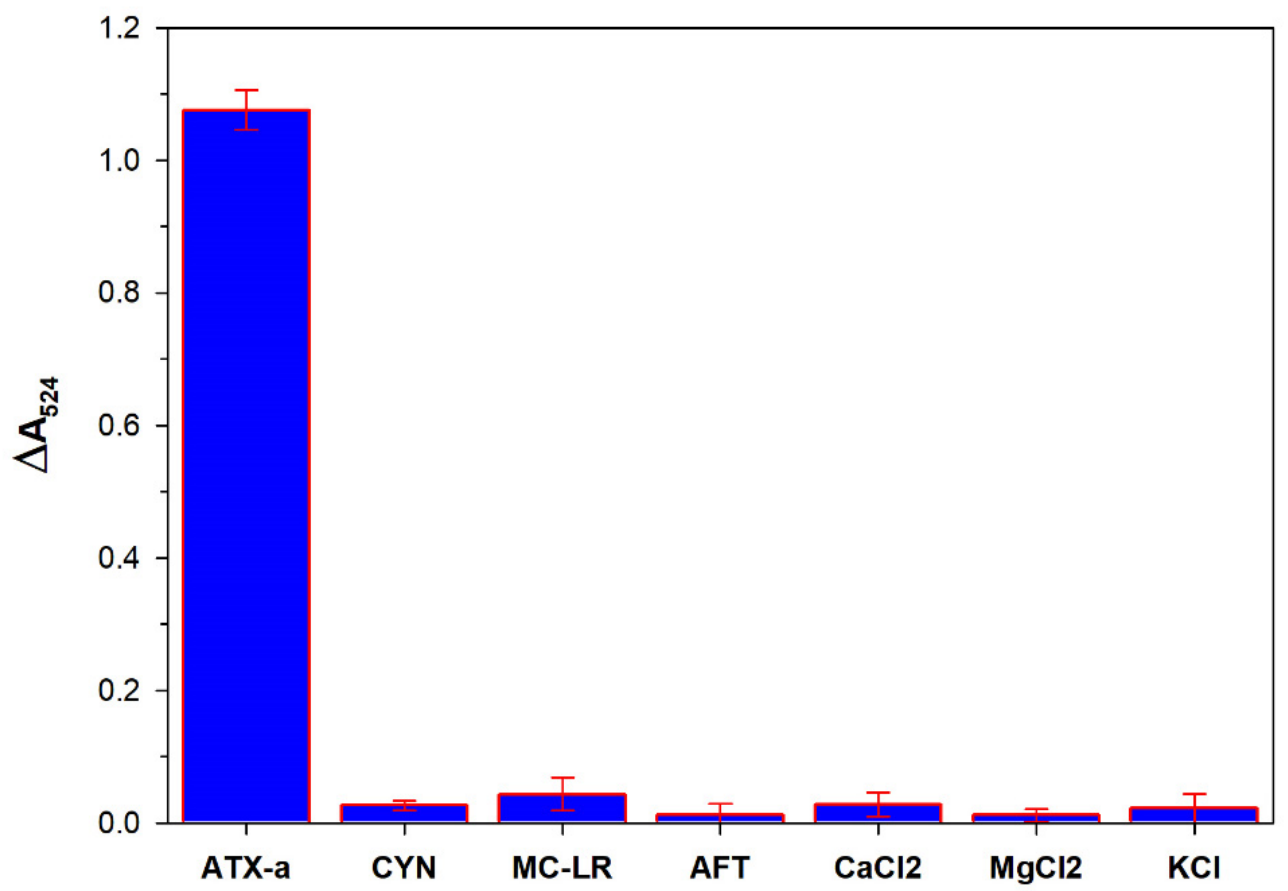

Figure 7. Specificity of the proposed colorimetric aptasensor for anatoxin-a (ATX-a). The ATX-a concentration was $200 \mathrm{nM}$. The concentration of other interferents was $1 \mu \mathrm{M}$.

\subsection{Analysis of Real Samples}

The performance of the developed colorimetric aptasensor for the detection of ATX-a in an actual water environment was then demonstrated. The natural water sample was obtained from a local lake (Shin Dae Lake, Suwon City, Republic of Korea), and different ATX-a concentrations were used to spike the samples, followed by analysis using the developed assay. The results, as summarized in Table 2, show that the recoveries were in the range of $89.72 \%$ to $112.43 \%$, and that the relative standard deviation (RSD) was between $4.12 \%$ and $10.91 \%$, indicating the acceptable accuracy of the developed aptasensor for ATX-a detection. These results demonstrate that the present biosensor has potential for monitoring ATX-a in real samples. 
Table 2. Determination of anatoxin-a (ATX-a) concentration in spiked lake water samples using our developed colorimetric aptasensor $(n=3)$.

\begin{tabular}{ccccc}
\hline Samples & Added ATX-a (nM) & Found ATX-a (nM) & Recovery (\%) & RSD (\%) \\
\hline Lake water 1 & 0.1 & 0.08972 & 89.72 & 8.15 \\
Lake water 2 & 0.5 & 0.4519 & 90.38 & 10.91 \\
Lake water 3 & 1 & 1.0419 & 104.19 & 2.98 \\
Lake water 4 & 50 & 56.215 & 112.43 & 6.37 \\
Lake water 5 & 200 & 195.7 & 97.85 & 4.12 \\
\hline
\end{tabular}

\section{Conclusions}

In summary, an aptamer-based colorimetric biosensor was developed for the detection of ATX-a in aqueous solutions using ATX-a-specific aptamers as the target recognition elements and AuNPs as colorimetric reporters. The change in AuNP aggregation was controlled by the interactions among the aptamer, AuNPs, and ATX-a in the presence of $\mathrm{NaCl}$ solution. The conformational change of the aptamer induced by the recognition of ATX-a caused a change in AuNP aggregation, resulting in a color change of the solution. This change was easily recorded using a UV/Vis spectrophotometer, and the obtained absorbance change generated a sensor signal for monitoring ATX-a. The relationship between the absorbance variation of the solution with and without ATX-a and the concentration of ATX-a was linear when the ATX-a concentration was in the range of $10 \mathrm{pM}$ to $200 \mathrm{nM}$. Compared to previously reported methods (Table 1), the developed biosensor has a lower LOD (4.45 pM) and a wider linear range (10 pM to $200 \mathrm{nM})$. Moreover, the proposed aptasensor exhibited high selectivity toward ATX-a against other interferents and displayed satisfactory recovery in the detection of ATX-a in real samples. Therefore, the proposed colorimetric aptasensor is a promising alternative method that offers a simple, rapid, and sensitive tool for ATX-a detection in the environment.

Supplementary Materials: The following are available online at https: / www.mdpi.com/article/ 10.3390/mi12121526/s1, Figure S1. (a) Optimization of the incubation time of aptamer with gold nanoparticles (AuNPs). (b) Optimization of the binding time of aptamer with anatoxin-a. Experimental conditions: concentration $(C)_{\text {AuNPs }}=4.7 \mathrm{nM}, \mathrm{C}_{\text {aptamer }}=125 \mathrm{nM}, \mathrm{C}_{\mathrm{NaCl}}=40 \mathrm{mM}, \mathrm{C}_{\mathrm{ATX}-\mathrm{a}}=100 \mathrm{nM}$.

Author Contributions: Conceptualization, D.-K.N. and C.-H.J.; methodology, D.-K.N. and C.-H.J.; investigation, D.-K.N.; data curation, D.-K.N.; writing—original draft preparation, D.-K.N.; writingreview and editing, D.-K.N.; visualization, D.-K.N.; supervision, C.-H.J.; funding acquisition, C.-H.J. All authors have read and agreed to the published version of the manuscript.

Funding: This work was supported by the Basic Science Research Program of the National Research Foundation of Korea (NRF) funded by the Ministry of Education (NRF-2019R1A2C1003862).

Conflicts of Interest: The authors declare no conflict of interest.

\section{References}

1. Elshafey, R.; Siaj, M.; Zourob, M. DNA aptamers selection and characterization for development of label-free impedimetric aptasensor for neurotoxin anatoxin-a. Biosens. Bioelectron. 2015, 68, 295-302. [CrossRef] [PubMed]

2. Sanchez, J.A.; Otero, P.; Alfonso, A.; Ramos, V.; Vasconcelos, V.; Aráoz, R.; Molgó, J.; Vieytes, M.R.; Botana, L.M. Detection of anatoxin-a and three analogs in Anabaena spp. cultures: New fluorescence polarization assay and toxin profile by LC-MS/MS. Toxins 2014, 6, 402-415. [CrossRef]

3. Carneiro, M.; Gutiérrez-Praena, D.; Osório, H.; Vasconcelos, V.; Carvalho, A.P.; Campos, A. Proteomic analysis of anatoxin-a acute toxicity in zebrafish reveals gender specific responses and additional mechanisms of cells tress. Ecotox. Environ. Safe. 2015, 120, 93-101. [CrossRef] [PubMed]

4. Namera, A.; So, A.; Pawliszyn, J. Analysis of anatoxin-a in aqueous samples by solid-phase microextraction coupled to highperformance liquid chromatography with fluorescence detection and on-fiber derivatization. J. Chromatogr. A 2002, 963, 295-302. [CrossRef]

5. Rodríguez, V.; Yonamine, M.; Pinto, E. Determination of anatoxin- $a$ in environmental water samples by solid-phase microextraction and gas chromatography-mass spectrometry. J. Sep. Sci. 2006, 29, 2085-2090. [CrossRef] 
6. Li, Z.; Zhang, S.; Yu, T.; Dai, Z.; Wei, Q. Aptamer-based fluorescent sensor array for multiplexed detection of cyanotoxins on a smartphone. Anal. Chem. 2019, 91, 10448-10457. [CrossRef]

7. Xia, M.; Zhou, F.; Feng, X.; Sun, J.; Wang, L.; Li, N.; Wang, X.; Wang, G. A DNAzyme-based dual-stimuli responsive electrochemiluminescence resonance energy transfer platform for ultrasensitive anatoxin-a detection. Anal. Chem. 2021, 93, 11284-11290. [CrossRef] [PubMed]

8. Zhu, L.; Zhao, Y.; Yao, S.; Xu, M.; Yin, L.; Zhaib, X.; Teng, X. A colorimetric aptasensor for the simple and rapid detection of human papillomavirus type $16 \mathrm{L1}$ proteins. Analyst 2021, 146, 2712-2717. [CrossRef] [PubMed]

9. Feng, J.; Zhu, Q.; Wang, Y. Colorimetric detection of Gadidae species using probe-modified gold nanoparticles. Food Control 2020, 116, 107287. [CrossRef]

10. Bala, R.; Kumar, M.; Bansal, K.; Sharma, R.K.; Wangoo, N. Ultrasensitive aptamer biosensor for malathion detection based on cationic polymer and gold nanoparticles. Biosens. Bioelectron. 2016, 85, 445-449. [CrossRef]

11. Ma, Q.; Wang, Y.; Jia, J.; Xiang, Y. Colorimetric aptasensors for determination of tobramycin in milk and chicken eggs based on DNA and gold nanoparticles. Food Chem. 2018, 249, 98-103. [CrossRef] [PubMed]

12. Kasoju, A.; Shrikrishna, N.S.; Shahdeo, D.; Khan, A.A.; Alanazi, A.M.; Gandhi, S. Microfluidic paper device for rapid detection of aflatoxin B1 using an aptamer based colorimetric assay. RSC Adv. 2020, 10, 11843. [CrossRef]

13. Chen, Z.; Tan, T.; Zhang, C.; Yin, L.; Ma, H.; Ye, N.; Qiang, H.; Lin, Y. A colorimetric aptamer biosensor based on cationic polymer and gold nanoparticles for the ultrasensitive detection of thrombin. Biosens. Bioelectron. 2014, 56, 46-50. [CrossRef] [PubMed]

14. Li, F.; Feng, Y.; Zhao, C.; Tang, B. Simple colorimetric sensing of trace bleomycin using unmodified gold nanoparticles. Biosens. Bioelectron. 2011, 26, 4628-4631. [CrossRef]

15. Baker, B.R.; Lai, R.Y.; Wood, M.S.; Doctor, E.H.; Heeger, A.J.; Plaxco, K.W. An electronic, aptamer-based small-molecule sensor for the rapid, label-free detection of cocaine in adulterated samples and biological fluid. J. Am. Chem. Soc. 2006, 128, 3138-3139. [CrossRef]

16. Wei, H.; Li, B.; Li, J.; Wang, E.; Dong, S. Simple and sensitive aptamer-based colorimetric sensing of protein using unmodified gold nanoparticle probes. Chem. Commun. 2007, 3735-3737. [CrossRef] [PubMed]

17. Chang, H.; Tang, L.; Wang, Y.; Jiang, J.; Li, J. Graphene fluorescence resonance energy transfer aptasensor for the thrombin detection. Anal. Chem. 2010, 82, 2341-2346. [CrossRef]

18. Li, J.; Zhong, X.; Zhang, H.; Le, X.C.; Zhu, J.J. Binding-induced fluorescence turn-on assay using aptamer-functionalized silver nanocluster DNA probes. Anal. Chem. 2012, 84, 5170-5174. [CrossRef] [PubMed]

19. Hamula, C.L.A.; Guthrie, J.W.; Zhang, H.; Li, X.F.; Le, X.C. Selection and analytical applications of aptamers. Trends Anal. Chem. 2006, 25, 681-691. [CrossRef]

20. Huang, Y.F.; Chang, H.T.; Tan, W. Cancer cell targeting using multiple aptamers conjugated on nanorods. Anal. Chem. 2008, 80, 567-572. [CrossRef] [PubMed]

21. Nguyen, D.K.; Jang, C.H. Label-free liquid crystal-based biosensor for detection of As(III) ions using ssDNA as a recognition. 22 probe. Microchem. J. 2020, 156, 104834. [CrossRef]

22. Zheng, Y.; Wang, Y.; Yang, X. Aptamer-based colorimetric biosensing of dopamine using unmodified gold nanoparticles. Sens. Actuators B Chem. 2011, 156, 95-99. [CrossRef]

23. Wu, Y.; Liu, L.; Zhan, S.; Wang, F.; Zhou, P. Ultrasensitive aptamer biosensor for arsenic(III) detection in aqueous solution based on surfactant-induced aggregation of gold nanoparticles. Analyst 2012, 137, 4171-4178. [CrossRef] [PubMed]

24. Tan, L.; Neoh, K.G.; Kang, E.T.; Choe, W.S.; Su, X. Affinity analysis of DNA aptamer-peptide interactions using gold nanoparticles. Anal. Biochem. 2012, 421, 725-731. [CrossRef]

25. Purohit, B.; Vernekar, P.R.; Shetti, N.P.; Chandra, P. Biosensor nanoengineering: Design, operation, and implementation for biomolecular analysis. Sens. Int. 2020,1, 100040. [CrossRef]

26. Kumar, A.; Purohit, B.; Mahato, K.; Roy, S.; Srivastava, A.; Chandra, P. Design and development of ultrafast sinapic acid sensor based on electrochemically nanotuned gold nanoparticles and solvothermally reduced graphene oxide. Electroanalysis 2019, 31, 1-12. [CrossRef]

27. Wang, Q.L.; Huang, W.X.; Zhang, P.J.; Chen, L.; Lio, C.K.; Zhou, H.; Qing, L.S.; Luo, P. Colorimetric determination of the early biomarker hypoxia-inducible factor- 1 alpha (HIF-1 $\alpha$ ) in circulating exosomes by using a gold seed-coated with aptamerfunctionalized Au@Au core-shell peroxidase mimic. Microchim. Acta 2020, 187, 61. [CrossRef] [PubMed]

28. Zhou, J.; Li, Y.; Wang, W.; Lu, Z.; Han, H.; Liu, J. Kanamycin adsorption on gold nanoparticles dominates its label-free colorimetric sensing with its aptamer. Langmuir 2020, 36, 11490-11498. [CrossRef] [PubMed]

29. Wang, R.; Yu, R.; Wang, Z.; Zhu, Q.; Dai, Z. A facile and sensitive colorimetric detection for RNase A activity based on target regulated protection effect on plasmonic gold nanoparticles aggregation. Sci. China Chem. 2020, 63, 860-864. [CrossRef]

30. Purohit, B.; Kumar, A.; Mahato, K.; Chandra, P. Smartphone-assisted personalized diagnostic devices and wearable sensors. Curr. Opin. Biomed. Eng. 2020, 13, 42-50. [CrossRef]

31. Wang, T.T.; Lio, C.K.; Huang, H.; Wang, R.Y.; Zhou, H.; Luo, R.; Qing, L.S. A feasible image-based colorimetric assay using a smartphone RGB camera for point-of-care monitoring of diabetes. Talanta 2020, 206, 120211. [CrossRef] [PubMed]

32. Liu, J.; Lu, Y. Preparation of aptamer-linked gold nanoparticle purple aggregates for colorimetric sensing of analytes. Nat. Protoc. 2006, 1, 246-252. [CrossRef] [PubMed] 
33. Li, H.X.; Rothberg, L. Label-free colorimetric detection of specific sequences in genomic DNA amplified by the polymerase chain reaction. J. Am. Chem. Soc. 2004, 126, 10958-10961. [CrossRef] [PubMed]

34. Nguyen, D.K.; Jang, C.-H. A Label-Free Liquid Crystal Biosensor Based on Specific DNA Aptamer Probes for Sensitive Detection of Amoxicillin Antibiotic. Micromachines 2021, 12, 370. [CrossRef] [PubMed] 